\title{
THE IMPERIAL COLLEGE OF SCIENCE AND TECHNOLOGY
}

\author{
NEW PHYSICS DEPARTMENT
}

\begin{abstract}
TN 1953 the Government decided that, within a 1 period of less than ten years, the size of the Imperial College of Science and Technology should be doubled. Plans were eventually prepared by the College for a massive expansion programme, involving the redevelopment of a large site in South Kensington, which culminated in the Jubilee scheme, announced by the College in 1957.

A significant stage in this expansion was reached on October 20, with the formal opening of the new physics building by Sir John Cockcroft. The Departments of Aeronautics and Chemical Engineering and part of the Department of Mechanical Engineering have already moved into new buildings during the past few years, but the Department of Physics is the first to be completely rehoused as part of the Jubilee scheme.
\end{abstract}

The new building has twelve floors (levels 0-11) in which the complete activities of the Department, both teaching and research, are carried out. Levels 0 and 1 are below ground-level, and levels 2-7, T-shaped in plan, rise $80 \mathrm{ft}$. above ground. Four more floors of smaller area (levels 8-I]) extend the spine of the $\mathrm{T}$ some $50 \mathrm{ft}$. higher. The given area of $183,000 \mathrm{sq}$. $\mathrm{ft}$. doubles the space provided by the old physics building, and it is interesting to note that this is provided on a site only half the size.

Teaching facilities are previded for $350-400$ undergraduate students, and are confined to levels $\mathbf{1 - 4}$, where large corridors and several staircases make for the easy movement of large numbers of students between lecture theatres and practical laboratories. There are three lecture theatres, the largest seating 250 and the others 150 each. The former is well equipped with ciné and still projectors, and with sound equipment. In addition to its use for undergraduate courses, it has been designed in conjunction with the entrance halls and the library reading room, with a view to the holding of scientific conferences.

The main practical instruction is given in three large teaching laboratories, each of which is provided with ancillary photographic dark rooms, preparation rooms and storage space. Library facilities have been considerably extended ; the book capacity is 12,000 volumes, and tables and seating for 100 persons are available day and night.

The teaching of undergraduates, concentrated on the lower floors of the building, has been further co-ordinated by the appointment of Prof. W. D. Wright, who continues also to hold the chair of technical optics, to the new post of director of undergraduate studies. He, assisted by several other members of the academic staff, will arrange the undergraduate courses and generally supervise the facilities for students in the teaching areas of the building.

Below ground-level are some very large rooms, used as research laboratories for acoustics, hightemperature physies and spectroseopy. Here, too,

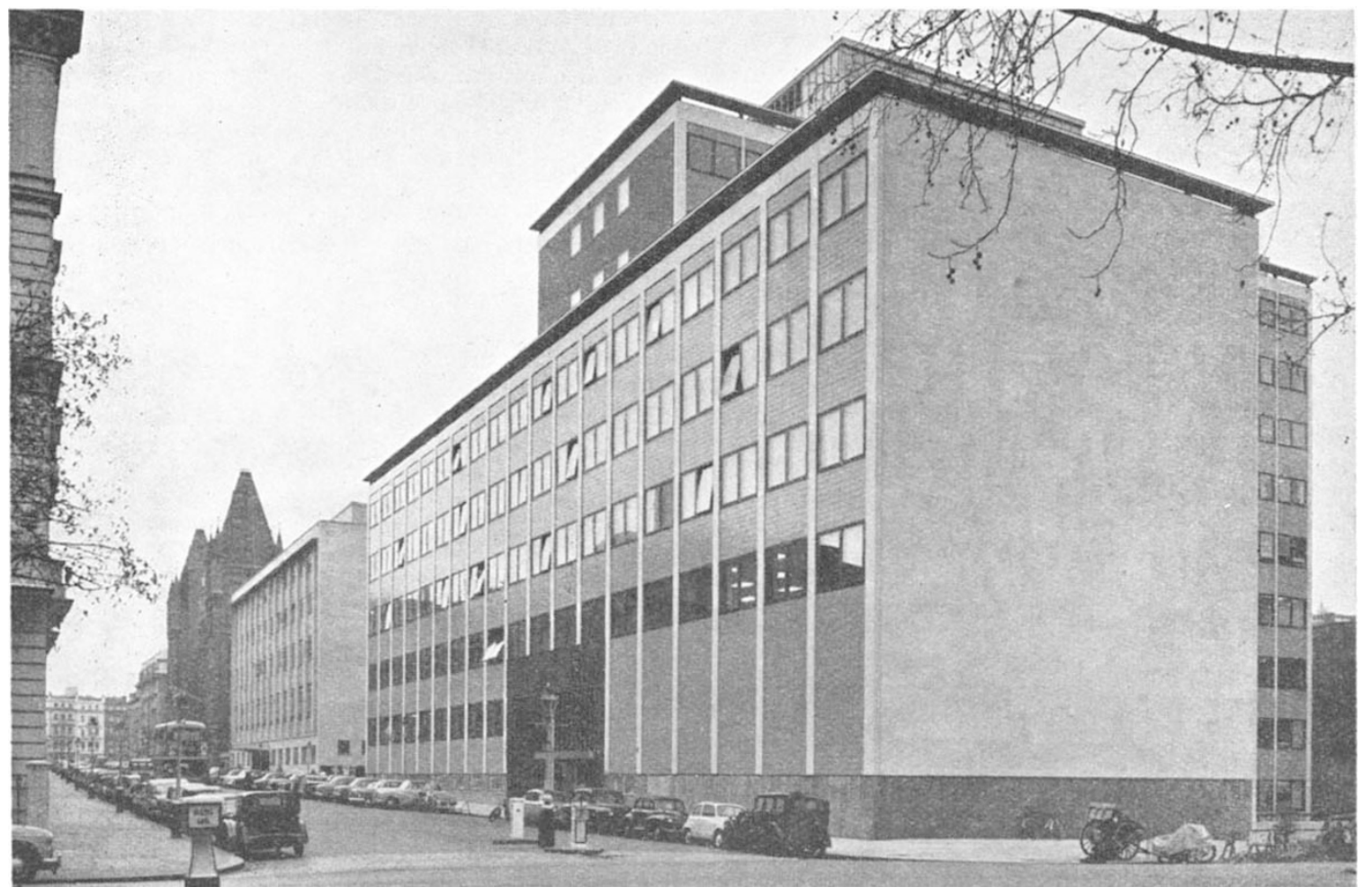

Fig. 1. New Physics Department of the Imperial College of Science and 'Technology, London 
are the students' and main workshops, used largely for the construction of research apparatus.

The main research activity, how ever, takes place on the upper floors of the building-levols 5-11. Although laboratories individually designed for various types of work offer advantages in the first few years to the first occupants of a new building, these are usually far outweighed by the difficulties of adapting them later for use for now poople and different research. Consequently, every effort has been made to avoid the specialized design of particular rooms. Throughout the research areas an attempt has been made to provide in rooms of all sizes a uniform high standard of background amenitios.

Largo, double-glazed windows provide good natural lighting, give acoustic and thermal insulation and can be blacked out completely or fitted with venetian blinds to avoid oxcessive glare or heating from the Sun. The building is completely ventilated with filtered air to minimize harm caused by dust on delicate apparatus and to reduce the inconvenience and cost of cleaning. Ceilings are faced with demountable acoustic tiles for quietness. These are also the source of heating, conceal some piped scrvices and support recessed lights, so that clear plane interior surfaces are provided without restriction on the placing of apparatus. To further this flexibility in the use of rooms, recessed wall racks and concealed attach. ment points in the ceiling are provided for the erection of apparatus.

Electrical supplies are contained in surface-mounted aluminium wall ducts, water and gas on narrow wooden service rails. These are provided in nearly all rooms, so that even the smaller ones, which may be used as academic staff rooms or administrative offices, can equally well be used for experimental work. Practically no laboratory furniture is built-in, but is composed of standardized units which can be grouped together and, if necessary, bolted to the wall racks, according to particular needs.

The large ducts above the corridor ceilings and vertical ducts in the thickness of the corridor walls interconnect all rooms in the building. Initially these carry only those minimal supplies of electricity, water and gas for the work at present envisaged, but as new projects arise and require new supplies,

readily accessible space in the ducts is available for them.

During the past five years a considerable expansion of the Department has already taken place, under great difficulties, in the old building, in preparation for the move into the new one. Physies undergraduates have increased by some 50 per cent to 315 , and postgraduates by a similar proportion to about 90. Approximately 100 undergraduates from other departments also attend courses. A particular feature of the Department's development is the number of independent research groups which have been formed, each headed by its own professor. In addition to the long-standing Technical Optics Section, three more have been established in recent years: Instrument Technology, Theoretical Physies and Cloud Physics. At the sarne time thrce other professors have been appointed to assist the head of the Department, Prof. P. M. S. Blackett, in the direction of its other research activities, which now include high-energy nuclear physics, cosmic rays, electron diffraction, high-temperature physics, spectroscopy, acoustics, rock magnetism, electron physics and metal physics.

That such an active and flourishing expansion in the Department's activities should be matched with the environment and facilities of what must be one of the finest physics buildings in the world, gives promiso of a great future for physics at the Imperial College.
N. C. BARFORD

\section{THE NATIONAL CHEMICAL LABORATORY}

\begin{abstract}
THE National Chemical Laboratory held open days for visitors from industry, the univorsities and Governmont departments during October 19-21. The Laboratory's work was last on view in October 1958 , shortly after the re-organization of the former Chemical Research Laboratory, so that this year's exhibition gave the first opportunity to inspect the changes and the progress made in implementing tho revised research programme. Especially noteworthy, perhaps, worc the increasing scope and facilities for
\end{abstract}

hydrometallurgioal research, and the docision to develop the earlier work on the purification and physical properties of organic compounds into a full programme of chemical thermodynamics. Although the open days showed also the progress in the Laboratory's continuing lines of research, emphasis was on newer developments.

The Extraction of Metals Group, concerned with hydrometallurgical processes and their underlying chemistry, showed its now laboratory wing, occupied 